\title{
LITERATURA E ANTROPOLOGIA COMO PARADIGMAS CRÍTICOS DO DIREITO
}

\author{
LITERATURE AND ANTHROPOLOGY AS CRITICAL PARADIGMS OF LAW
}

\author{
Guilherme Grané Diniz*
}

\begin{abstract}
Resumo:
O pensamento de crítica do Direito já é muito antigo em nossa sociedade, encontrando desde seus primórdios diversos paradigmas. No passado, a filosofia foi o principal paradigma e com o advento da modernidade e do positivismo filosófico, a ciência passou a ocupar este lugar. No presente artigo, em primeiro momento, exploramos como a antropologia funciona enquanto um paradigma crítico do Direito, a partir do descentramento do olhar ocidental sobre suas instituições e consequente desnaturalização da ideia da universalidade do Direito. Para tanto, exploramos alguns textos postos pelo antropólogo contemporâneo Robert Vachon. Mas, no segundo passo deste trabalho, queremos mostrar que a antropologia encontra limitações para essa crítica no fato de estar atrelada culturalmente à modernidade social, de modo que em uma crítica que busca descentrar de forma absoluta de nossas categorias ela incorre no que Habermas chama de contradição performativa. Desse modo, pretendemos propor a literatura como um paradigma crítico do Direito que não sofre com os ônus enunciativos que a antropologia traz, podendo fazer assim uma crítica mais profunda e consequente.
\end{abstract}

Palavras-chave: Antropologia do Direito. Literatura. Vachon. Bataille. Sade.

\begin{abstract}
:
Critical thinking of Law and its paradigms are, in fact, very old in our society. In the past, philosophy was the main paradigm but, since the advent of modernity and philosophical positivism, science came to occupy this place. In this paper, the author explains how anthropology may be as a critical paradigm of Law, from the decentering of the Western view on the institutions and consequent denaturalization of the idea of the universality of Law. To do so, some texts written by the contemporary anthropologist Robert Vachon were analyzed. In the second part of this paper, the author demonstrates that anthropology finds limitations to this critic, due to the fact that it is culturally linked to social modernity, so that in a critic that seeks to decentralize categories by an absolutely way, it incurs in which Habermas defined as performative contradiction. The author proposed literature as a critical paradigm of Law, because that does not suffer from the enunciative limits in Anthropology, what allows a deeper and consequent criticism.
\end{abstract}

Keywords: Anthropology of Law. Literature. Vachon. Bataille. Sade.

Guilherme Grané Diniz é advogado, bacharel em Direito pela Universidade presbiteriana Mackenzie, graduando em Filosofia pela Universidade de São Paulo e mestrando em Filosofia e Teoria Geral do Direito pela mesma Universidade. E-mail para contato: guilhermegranediniz@gmail.com. 
A crítica ao Direito é um movimento teórico antigo e muito relevante para o pensamento jurídico ocidental. O principal recurso crítico da tradição parece ter sido a filosofia. Já os pré-socráticos falavam em seus aforismas, poemas e discursos sobre o Direito. Platão e Aristóteles são autores ainda hoje estudados nos cursos de ciências jurídicas justamente pois utilizaram-se de ferramentas filosóficas para construir raciocínios críticos acerca do Direito como um todo e do Direito de seu tempo. Ao longo da história da filosofia, o Direito manteve uma preocupação constante. Já na contemporaneidade, os autores que serão considerados como pilares e linhas de força no pensamento desta época (que por sinal é a nossa) ainda estão pensando e articulando questões referentes ao Direito. Freud, Marx e Nietzsche (os fundadores do pensamento contemporâneo, segundo Foucault (MARTON, 2009, p. 45); isto sem contar com o próprio) não descuidam de dar lugar destacado ao Direito, à normatividade, às diversas manifestações da lei e questões a isso correlatas em seu pensamento. Enquanto fundadores de um novo estilo de pensar, eles influenciaram um grande número de outros filósofos, os quais seguindo na esteira de seu pensamento também se mantêm constantemente mobilizados por questões acerca do Direito. Bataille, Heidegger, Foucault, Derrida... seja de forma central ou lateral, direta ou indireta, a questão sobre o Direito ou às diversas figuras da normatividade está presente em suas obras.

Mas decerto que a filosofia não é a única forma de se criticar o Direito. Existem outras, cada qual dotada de suas características peculiares de um ponto de vista teórico. Consideremos aqui, ainda de maneira inicial, uma certa ideia de crítica antropológica do Direito; depois nos aprofundaremos nela. A antropologia é uma ciência que em seu momento constitutivo tem a pretensão de estudar os povos "primitivos" ou "autóctones"; também se dá a estes povos outras denominações. O importante de termos em mente é que inicialmente o objeto do saber antropológico era justamente aquelas sociedades que não eram a nossa; as sociedades não ocidentais. Contemporaneamente, a antropologia passou por muitos desenvolvimentos em relação àquele seu momento inicial, e se busca defini-la mais como uma forma específica de lançar um olhar sobre as sociedades do que por meio de seu objeto. Ainda assim, mesmo quando se dedica a observar o mundo urbano e ocidental, a antropologia o faz geralmente pelo viés das populações marginalizadas, minoritárias e excluídas da população. Talvez este seja naturalmente o enfoque privilegiado daquela forma de olhar antropológica. De qualquer modo, entende-se que uma das características mais preciosas do estudo antropológico consiste no fato de que ele pode nos revelar, seja dentro ou fora de nossa própria sociedade, aquelas experiências e formas de vida que não correspondem às hegemônicas. Ela promove um descentramento de nossa vivência ocidental moderna e nos dá acesso à experiência de mundo a partir de visões alternativas. É bem certo que isto encontra algumas limitações metodológicas, mas em termos bastante gerais, esta é a pretensão da antropologia. Seu potencial crítico em relação ao Direito é 
bem claro, então. Encontrando formas diferentes de estruturar a experiência do mundo em outras sociedades, a antropologia nos permite repensar de forma muito profunda nossas categorias jurídicas, permitindo, no limite, repensar mesmo a universalidade do Direito enquanto categoria.

Sob a alcunha de antropologia correm estudos desde há muito tempo. ${ }^{1}$ Mas, em seu sentido mais próprio, a antropologia se estrutura como um saber científico a partir do fim do século XIX. Quando dizemos que ela nasce com o estatuto de ciência, existe algo muito específico envolvido nisto. Isto porque com o advento da modernidade o sentido de ciência mudou fortemente. No horizonte mais abrangente que marcava a época de seu surgimento estavam a Revolução Industrial e o neocolonialismo; corolários do processo de modernização. Neste sentido, a ideia iluminista de progresso era uma marca do pensamento antropológico, o qual se revelava fortemente evolucionista. Isto condiz muito com o que dizíamos sobre o estatuto científico na modernidade. Naquele momento, ciência passou a ser não simplesmente a busca pelo conhecimento, mas a busca pelo conhecimento útil e aplicável. A antropologia nasce com a pretensão de estudar os povos autóctones, mas, uma vez inserida no contexto neocolonialista, o saber que ela produz é altamente instrumental na dominação destes povos. O estado da arte certamente mudou bastante desde aqueles momentos iniciais. Em boa parte, o projeto antropológico hoje envolve menos a tentativa de intervir nas sociedades ditas primitivas, mas sim buscar nelas o conhecimento para intervir na nossa. Mas mesmo quando hoje se tenta conceber a antropologia a partir de um paradigma mais inclusivo e pluralista, ela ainda guarda em si marcas fortes de sua matriz epistemológica: a modernidade.

Jurgen Habermas tem como um dos temas centrais de sua vasta obra filosófica a questão da modernidade. Na verdade não se trata exatamente de uma questão única, mas sim de um vasto complexo de indagações que se centram ao redor deste tema mais amplo. Não bastassem os diversos estudos assaz elucidativos a respeito do fenômeno moderno propriamente dito, um tipo de abordagem extremamente relevante que o autor realizou deste tema envolve os diversos modos pelos quais ele foi teoricamente apropriado, ou seja, além de estudar o fenômeno sociocultural "modernidade", buscou estudar também o discurso, especialmente o acadêmico, que sobre ele se constituiu. Este estudo foi realizado tanto no âmbito da sociologia, na obra "Teoria do Agir [ou da Ação, como preferem alguns tradutores] Comunicativo" (2012), quanto na filosofia, que podemos encontrar no livro "Discurso Filosófico da Modernidade" (2002). Aqui ele buscará analisar detidamente a obra de alguns filósofos que são considerados mais relevantes dentro da filosofia moderna (seu entendimento de filosofia moderna não é exatamente o mesmo que o da maioria

Para todo este trecho, cf. ROULAND, 2008, p. 69-74. 
dos autores, este ponto é muito relevante e será explicado mais adiante) e apontar as insuficiências que seus trabalhos revelam no que tange à solução das questões chaves postas pela modernidade cultural.

Hegel é o autor que identificou as regras do jogo moderno, é em sua obra que a modernidade passa pela primeira vez a compreender a si mesma como um problema em termos de história humana que precisa ser resolvido (HABERMAS, 2007, p. 4). Seus seguidores, à direita e à esquerda, principalmente estes, são fortes críticos da modernidade e suas instituições (HABERMAS, 2007, p. 56); basta considerarmos que dentre eles encontram-se os marxistas e as correntes da esquerda política que inicialmente derivam de seu pensamento. Ao mesmo tempo em que elas criticam a modernidade, principalmente na forma das relações econômicas que subjazem à estrutura social como um todo, eles deixam intactas as matrizes teóricas e históricas que a originam. Na verdade, o diagnóstico que subjaz a sua crítica é principalmente o de que os principais problemas enfrentados pelas sociedades modernas consistem mais numa falta de racionalidade que no excesso dela (HABERMAS, 2007, p. 65), ao contrário da corrente oposta à modernidade como um todo que se concentra no fato de que a racionalização das formas de vida não seria sequer um projeto desejável em termos gerais.

Quando Nietzsche escreve sua obra, ele inaugura um momento novo no que concerne o discurso filosófico vigente até então (HABERMAS, 2007, p. 85). Sua crítica à modernidade se faz de forma tal que tem por finalidade negar seus principais fundamentos teóricos e propor que se os substitua. Hegel percebeu a modernidade como uma época de ruptura radical com todo tipo de experiência histórica que a humanidade até então havia experimentado. Esta intuição fundamenta toda autocompreensão cultural da modernidade. É dela que deriva um dos principais traços de toda a filosofia moderna, que é a busca por uma fundamentação normativa para esta época. Ainda mais, os acontecimentos que estão na base do surgimento da modernidade e a conformam enquanto experiência de mundo já dão algumas diretrizes para esta nova fundamentação normativa. Sem entrar no mérito de observar o tema em detalhe, trata-se de afirmar a modernidade como a era da razão. É neste cenário que se põe a obra de Nietzsche (HABERMAS, 2007, p. 84). De início, entende-se que a modernidade deveria fundamentar-se a partir de seus próprios princípios, mas ele busca fundamentos normativos para esta época a partir de seu outro. Isto significa em essência o abandono do paradigma da razão totalizante em prol de um pensamento esteticamente fundamentado, além da dissolução da categoria da subjetividade autorreferencial por meio da experiência dionisíaca, que também é um tipo de forma estetizante de experimentar o mundo (NIETZSCHE, 2012, p. 29). Ele inclusive procura o auxílio de um passado exemplar, a helenidade clássica, de modo que rompe com esta regra do jogo da autocompreensão moderna (NIETZSCHE, 2012, p. 94). Nesta forma de articular a questão, a modernidade teria se dado não como ruptura radical, mas como 
uma ruptura progressiva com a cultura trágica grega iniciada por Sócrates e Eurípides (NIETZSCHE, 2012, p. 89) e que atinge seu ápice com a "morte de Deus", que representa a perda total da já combalida capacidade do homem de criar valores para sua existência; o ponto extremo de uma tendência de niilismo fraco (MACHADO, 1997, p. 55). É claro aqui como se trata de uma oposição à modernidade e ao que ela representa. Da obra de Nietzsche surge uma forte tradição crítica que se colocará como pós-moderna, justamente no sentido de que pretende superar ou ter superado a modernidade. Nesta estarão aqueles que, por diversas vias, buscarão seguir os caminhos abertos por Nietzsche e realizar uma crítica totalizante da razão (HABERMAS, 2007, p. 97).

Dentre os vários autores que pensam dentro desta corrente, podemos encontrar Georges Bataille. Este autor escreve na França do início e metade do século XX uma obra realmente muito singular. De partida, cumpre dizer, Bataille sequer tinha formação em filosofia, era um biblioteconomista e arquivista, sendo que sua única aproximação com o meio acadêmico foi o já quase mítico curso que Alexandre Kojéve ministrava sobre a Fenomenologia do Espírito, de Hegel (SABOT, 2012, p. 2). Neste, teve contato com autores capitais da França de sua época, tanto na filosofia, como Merleau-Ponty e Jacques Lacan, quanto na literatura, como Andrè Breton, e adquiriu uma das principais bases para toda sua produção intelectual. Talvez seja, na verdade, justamente esta a grande peculiaridade de sua obra do ponto de vista filosófico. Bataille foi um autor que buscou acoplar uma constelação de referências que incluíam, e não se limitam a: a dialética hegeliana (MELTZER, 2006, p. 17); o impacto fulminante que uma leitura peculiar de Nietzsche começava a ter sobre todo o cenário cultural francês da época (a respeito disto $c f$. MARTON, 2009); a antropologia, por meio das obras de Levi-Strauss (BATAILLE, 2013b, p. 224) e Marcel Mauss (BATAILLE, 2013a, p. 79) e a reapropriação da obra de Sade, empreitada levada a cabo pela literatura surrealista, círculo do qual Bataille era muito próximo (SCHEIBE in BATAILLE, 2013b, p. 11). Por outro lado, Habermas verá nesta peculiaridade, este amálgama que beira a incoerência de paradigmas contrastantes, sua principal fraqueza (em tempo chegaremos a este ponto). Em sua filosofia, Bataille é guiado por um horizonte bastante curioso de questões, que cumpre tentar colocar em perspectiva ao longo do desenvolvimento conceitual encontrado dentro de algumas de suas obras centrais.

Uma chave de leitura - frise-se, dentre as várias possíveis - pela qual podemos adentrar sua obra é a da economia política. Bataille realiza sua análise da economia subvertendo a lógica do estudo da economia clássica e mesmo a do (de algum tipo de) marxismo, ao menos em um primeiro momento. Enquanto os autores em geral estudam a troca a partir da ideia paradigmática de uma escassez de recursos na natureza, a ser superada pelo trabalho, ele buscará enxergar numa perspectiva ampliada o excesso de forças que permite o consumo luxuoso, o gasto excessivo (BATAILLE, 2013a, p. 21), 
realizando assim uma economia política do dispêndio. Não se trata apenas de um parti pris metodológico, o que Bataille propõe é que a própria economia enquanto fato social se estrutura a partir do dispêndio; os economistas clássicos foram cegos em relação a isto. A afirmação ficaria clara quando se olhasse para o instituto da troca. Na verdade, estaria subjacente ali o potlatch (este é um tema que ele extrai da antropologia jurídica de Marcel Mauss) como origem de toda atividade econômica humana (BATAILLE, 2013a, p. 24). O potlatch é um sistema de prestações de caráter agonístico. Isto quer dizer que ela tem por fulcro não efetivamente realizar trocas de bens - Bataille bem lembra que o potlatch ideal seria aquele que o grupo que recebe não teria como retribuir (BATAILLE, 2013a, p. 26) - mas sim humilhar e subjugar o grupo rival pela demonstração de poder que ficaria evidente pela eliminação dos bens que poderiam ser consumidos. Um grupo de pessoas, geralmente em uma ocasião festiva, oferece um grande banquete ou um grande dom em presentes a outro, ou ainda destrói em frente ao outro grupo uma quantidade significativa de seus bens (BATAILLE, 2013a, p. 24-25). Os grupos rivais que recebem a prestação tem o dever de retribuí-la e ainda pagam uma espécie de juros; quanto mais demoram na retribuição maior deverá ser o desperdício de bens realizado. É deste modo acidental que pelo potlatch se gera algum tipo de riqueza (BATAILLE, 2013a, p. 25). Estes bens devem ser entendidos em sentido lato, pode se tratar inclusive de mulheres e escravos. Em relação à forma, também o potlatch é algo deveras amplo, já que as estruturas que subjazem a esta formação se estendem inclusive às sociedades capitalistas. A riqueza se ligava à posição social apenas na medida em que ela se utiliza de algum modo improdutivamente; Bataille dá de exemplos as festas, espetáculos e jogos (BATAILLE, 2013a, p. 27). Com o aprofundamento da racionalização e da cristianização da sociedade, as manifestações mais fortes do dispêndio no capitalismo passaram para o âmbito do privado, mas ainda restou o consumismo e a ostentação do luxo (BATAILLE, 2013a, p. 28). De tudo o que foi posto, percebe-se que os economistas clássicos e os economistas políticos teriam diagnosticado mal o problema central do qual deveriam partir; as relações de troca que de algum modo teriam dado origem a toda forma de relação econômica mais complexa não encontrava sua razão de ser numa escassez originária referente à própria natureza, mas sim na resposta aos desafios políticos da abundância. ${ }^{2}$

Mencionamos en passant logo acima, mas é da essência do problema e de sua solução percebermos no detalhe como esta economia invertida de Bataille está ligada justamente a sua noção de natureza. Esta parece que é um de seus primeiros e

2 A descrição que Bataille realiza do instituto do Potlach neste ensaio segue muito de perto o trabalho antropológico de Marcel Mauss "Ensaio sobre a Dádiva", o interessante é notar como ele extrai consequências mais radicais do ponto de vista da economia política, o que será articulado depois por meio de sua noção de dispêndio dentro de uma economia geral. 
principais vínculos teóricos com a obra do Marquês de Sade. É perceptível que conceitos, Bataille nos dá poucos; ele é mais afeito às fórmulas e enunciações. Natureza, também ele não conceituará de modo positivo. Na sua obra "O Erotismo" o autor procederá a mostrar o modo especial pelo qual o homem se relaciona com ela. Trata-se de entender uma dialética entre o interdito e a transgressão, pois é por meio do interdito que o homem se separa da natureza, e ao superar o interdito através da transgressão o homem consegue atingir novamente a natureza, mas, ainda assim, de modo mediado justamente por um interdito superado dialeticamente. Ao fim, cabe considerar então que o homem nunca pode realmente acessar a natureza, não existe uma natureza humana ou um ser natural para o homem, apenas existe uma experiência propriamente humana da natureza, mas que é sempre mediada pela cultura ou pela negação da cultura. Esta forma especial de retomada da natureza pelo homem é por ele chamada de erotismo. O homem institui o interdito por um motivo específico, e este podemos perceber se analisarmos os primeiros interditos que o homem criou; os relativos à morte (especificamente ao cadáver) e ao sexo (BATAILLE, 2013b, p. 65).

O primeiro deles se encontra já formulado na Bíblia, sob a forma do quinto dos mandamentos (BATAILLE, 2013b, p. 65). Temos dele o testemunho arqueológico das tumbas e dos ritos de inumação dos corpos praticados pelos homens mais antigos. Podemos afirmar com alguma segurança a existência destes cuidados pra com o cadáver a partir do momento em que podemos identificar as técnicas de preservação e enterro do corpo, que surgem com o homo sapiens do paleolítico médio (BATAILLE, 2013b, p. 67). Seja como for, o que estes cuidados denotam é a consciência de que o cadáver não é apenas um objeto entre objetos, mas um signo do destino de cada indivíduo (BATAILLE, 2013b, p. 68). Assim, a recusa de tocar o cadáver ou de ver e lidar com o cadáver é também de algum modo a recusa da tomada de consciência da possibilidade de que em algum momento nossa subjetividade venha ser destruída e nós passemos a ser algum tipo de objeto. Este cessar da vida tem sempre na consciência do homem sentido de uma violência contra o ser, mais especificamente o sentido de uma desordenação que se opunha contra a ordenação do mundo do trabalho (BATAILLE, 2013b, p. 70). Entendiase que toda morte era um tipo de assassinato, fosse literalmente ou pelo uso de algum tipo de magia. A questão é que sempre existem forças positivas atuantes que causam a morte e sempre existem responsáveis. Assim, o interdito contra a morte é um interdito contra a própria violência. $\mathrm{O}$ morto, em princípio um colega, parente, amigo, etc., era cooptado ao mundo da violência. O horror ao cadáver, na consciência primitiva, vinha justamente da crença na possibilidade de contaminação por esta violência desordenada, como acontecera ao que morrera e poderia se espalhar entre os vivos, o que se percebia no próprio cadáver quando ele começava a se decompor. Neste sentido, ambos os interditos em relação ao cadáver, tanto o de tocar quanto o de produzir, estão submetidos à mesma 
lógica, evitar a propagação da violência (BATAILLE, 2013b, p. 71-72). Ainda assim, é de se considerar que este não é própria ou unicamente o sentido último do interdito, mas em tempo explicaremos o porque.

A outra forma que o interdito tomou em um primeiro momento foi do interdito em relação ao sexo. Os registros deste tipo de interdito não são tão antigos, o que decerto não nos impede de, mas também não nos permite, supor que ele possa ser tão antigo quanto o outro. As primeiras representações que encontramos do homem são do período paleolítico superior e tem principalmente por conteúdo a atividade sexual (BATAILLE, 2013b, p. 73). Também este tipo de interdito se constrói em oposição a um reino do trabalho. O sexo é capaz de desestabilizar, de literalmente atrapalhar a atividade laboral, portanto é necessário que ela seja excluída do mundo do trabalho. Este interdito recebe formas variadas dentro das diversas sociedades (BATAILLE, 2013b, p. 74). Uma primeira bastante interessante é o interdito em relação ao incesto. Este cria uma série de regras de alta complexidade para definir o horizonte possível de relações sexuais cujo fim último é impedir que a violência desestruture a própria sociedade, que é condição para todo tipo de interação ${ }^{3}$ (BATAILLE, 2013b, p. 75-76). Talvez mais significante sejam os interditos relativos ao sangue que decorre da menstruação ou do parto, já que eles remetem a uma violência interna ao ser. O parto ainda mais, já que se trata da desmesura pela qual algo passa por uma mudança qualitativa, do não-ser ao ser, no sentido inverso da morte (BATAILLE, 2013b, p. 78). O ponto na verdade é justamente que existe uma afinidade em nível "estrutural" entre a morte e a atividade sexual, especialmente quando esta se liga à genitalidade (reprodução). ${ }^{4}$ Esta afinidade se dá no fato de que ambos são um tipo de violência.

"A morte de alguém é correlata ao nascimento de outro alguém" (BATAILLE, 2013b, p. 79). Esta é a tônica do argumento de Bataille. Ao morrer, uma pessoa disponibiliza a matéria da qual é feita seu corpo à decomposição, que é o retorno das matérias da qual ele é composto à natureza. Isto é condição para que surja uma nova pessoa ou um novo ser, humano ou não; a natureza usa de matéria-prima para a criação de novos seres justamente este elemento informe que se origina da morte daquilo que vive. Por isso que o horror ao cadáver apenas dura o período de sua putrefação, pois é durante este tempo em que ele é o signo fermentante do retorno de tudo o que vive à matéria inanimada de onde veio primordialmente - o retorno do homem ao pó. Quando apenas sobram os ossos o processo de "coisificação" do corpo já está encerrado, e o homem pode

3 Devemos chamar a atenção para como Bataille está inscrevendo o trabalho de Levi-Strauss dentro do seu.

4 A questão de se a atividade sexual se liga ou não à reprodução é sempre essencial, pois que ambas tem sentidos muito diversos. É claro que não cabe fazer, ou melhor, tentar fazer, uma tipologia destes sentidos, mas observá-los na medida em que aparecerem. 
lidar novamente com o cadáver. Isto vale para a consciência do homem "primitivo"; para nós vigem outras regras, derivadas destas (BATAILLE, 2013b, p. 80). A manifestação no sujeito deste interdito é o nojo ou náusea, que se constitui no vazio do desfalecimento. $\mathrm{O}$ vazio é o signo deste nojo, tanto o desfalecimento é seu paroxismo quanto ele se dá pelo vazio do cadáver, pela putrefação que se constrói sobre este vazio (BATAILLE, 2013, p. 81). A repugnância é o elo entre a atividade sexual e a morte. Assim como nos recusamos a ver um cadáver, existe uma recusa a presenciar o ato sexual. $\mathrm{O}$ desejo tem por origem justamente esta recusa inicial. Esta passagem da recusa (vazio) para o desejo é como a passagem do nada ao ser, é a desmesura. Assim, todo desejo sexual tem por fundamento um ato de excesso, de negatividade, que se pela dicotomia inicial entre vida e morte que pusemos (BATAILLE, 2013b, p. 84). Assim, Bataille pode fundar toda a criação sobre o dispêndio e o desequilíbrio. A cadeia alimentar é fundada também neste dispêndio; herbívoros comem montanhas de plantas para se manterem vivos, um animal carnívoro deve comer vários herbívoros (BATAILLE, 2013b, p. 85). Isto remete certamente a um dispêndio de energia inevitável interior ao ser. Tudo indica o procedimento próprio da natureza: o gasto dispendioso; o contrário de uma lei de economia dos meios.

Enfim podemos perceber que os interditos que o homem institui tem um objeto: a natureza. Esta é que opera em um regime de desmesura, gasto incontrolável, que subtrai o homem de seu trabalho e o obriga a, enquanto parte da natureza também, participar deste dispêndio de algum modo, mesmo que contra sua vontade imediata e apenas durante certos lapsos temporais. A natureza atua deste mesmo modo tanto nos indivíduos quanto em suas relações. Ainda, é essencial atinarmos a natureza com seu sentido fundamental; violência. Ora, vimos que esta é justamente a recusa comum entre os interditos contra a morte e contra o sexo, ou seja, é o que subjaz a ambas as atividades. A razão é a atividade realizada pelo homem com a finalidade de furtar-se à natureza, de manter-se na existência sem estar sujeito ao fluxo de destruição e instabilidade. Ela é o sentido fundamental do interdito. É deste modo que devemos colocar a oposição entre interdito e transgressão; como a oposição entre uma atividade racional produtiva e a natureza dispendiosa que clama por nós incessantemente. O interdito não é simplesmente superado pela transgressão, mas complementado por ela. Nunca o romper-se de uma regra tornou-a inválida, pelo contrário, é rompê-la que dá sentido a sua existência enquanto regra (BATAILLE, 2013b, p. 64). Ainda assim, quando o homem consegue levar a cabo o projeto de racionalização da modernidade fica absolutamente prescrita de todas as formas sociais a possibilidade da transgressão efetiva. Os dados do problema são estes, como Bataille os manipula no sentido de constituí-los em uma crítica à modernidade é um problema um tanto mais complexo, mas se devemos indicar um caminho para entender isto, certamente passa pela articulação destes temas com o surgimento do nazifascismo. 
Em seu ensaio sobre o nazismo, Bataille nota uma dificuldade para seu estudo. Ela encontra-se justamente no que ele delineia como seu objeto. A ciência trabalha por meio da homogeneização, tornando as coisas comensuráveis e racionais (BATAILLE, 1989, p. 141). Quando ele se propõe a estudar cientificamente o heterogêneo, ele é obrigado a inserir na ciência aquilo que não se presta já de início a ser seu objeto. Fica indicado que uma possibilidade para atingir tal conhecimento é o pensamento místico dos primitivos ou os sonhos, caso no qual se invoca a psicanálise (BATAILLE, 1989, p. 142). Talvez por isso que o ensaio se proponha a analisar a estrutura psicológica do fenômeno fascista. Ainda assim, este problema é complexo e o autor não chega a positivamente dar uma solução dentro deste ensaio. Habermas chama atenção para esta questão como sendo um defeito estrutural em sua filosofia. $\mathrm{O}$ autor parece querer realizar uma síntese impossível entre elementos da razão e da desrazão. Em tese, seria impossível fazer uma teoria científica sobre os elementos heterogêneos da sociedade, posto que em contato com eles o próprio sujeito cognoscente, pressuposto de todo conhecimento científico, é implodido na experiência dionisíaca ou erótica (HABERMAS, 2007, p. 235-236). Bataille não poderia ter sido ingênuo ao ponto de ter tentado realizar tal tipo de estudo, ele mesmo fez sua crítica ao considerar sobre o Relatório Kinsey, o qual traz uma série de análises e medições pretensamente objetivas sobre a atividade sexual dos norteamericanos. A questão é que o estudo do sexo envolve, naturalmente, o contato com a atividade sexual alheia, e confrontado com esta, o ser humano nunca fica indiferente, ele é como que contagiado, atraído para ela e não pode mais manter-se objetivo em seu estudo (BATAILLE, 2013b, p. 178). Os dados do relatório Kinsey então não são simplesmente dados quantitativos, mas observações que vão desde o voyeurismo de saber o número de orgasmos do adulto médio até a curiosidade pedofílica pela masturbação em bebes $^{5}$ (BATAILLE, 2013b, p. 181). O próprio autor considera isto um avanço da parte do relatório, mas para Habermas, Bataille fica preso entre dois tipos de pensamento diferentes e inconciliáveis, aquele da ciência e da racionalidade e o da desmesura e do erotismo. Por isto dizíamos que talvez uma de suas fraquezas principais do ponto de vista teórico seja a combinação de influências incompatíveis. Por um lado a dialética hegeliana seria uma forma de pensar a relação entre interdito e transgressão, mas fazendo recurso a esta, ele retornaria ao jogo da modernidade do qual ele se propôs fugir em um primeiro momento ao adotar o ponto de vista de Nietzsche. Não traremos aqui a comparação da obra de Bataille com a dele pois isto complicaria ao invés de simplificar, mas Habermas aponta como em certo sentido a dualidade entre interdito e transgressão, superada pelo erotismo, é um eco ou retomada do tema da dualidade entre apolíneo e dionisíaco, que

Não poderíamos deixar de notar como se insinua aqui o tema foucautiano da intercomunicação entre prazer e saber, que por sinal é uma trilha comum entre Nietzsche, Foucault e Bataille. 
se encontrariam reconciliados na tragédia (HABERMAS, 2007, p. 211). Ora, o próprio Nietzsche reconhece que errou em sua obra "O Nascimento da Tragédia", dentre outros motivos, por ter sido pego pelo jogo hegeliano (NIETZSCHE, 2008, p. 59). Isto é só cogitação. O que sabemos é que Habermas dá um nome específico a este tipo de engano teórico: contradição performativa.

O Iluminismo foi a princípio a racionalização do mundo, o aplicar a razão a ele de modo a estruturá-lo e permitir que se o desencantasse. Este tema foi uma das principais investigações da obra de Max Weber. Para ele, a relação dentre modernidade e racionalidade, mais particularmente do modo como ela se deu no ocidente, era intrínseca, e não contingente, as ciências modernas permitiram conhecer melhor a lógica interna de esferas culturais de valor (HABERMAS, 2007, p. 1). Isto é senão o resultado da filosofia kantiana, que permitiu à razão enquanto faculdade crítica servir de juiz para todas estas esferas de valor que agora legitimavam-se em seus próprios termos (HABERMAS, 2007 , p. 18-19). Foi questão de tempo até que estas esferas, antes cindidas na interioridade do sujeito separassem-se institucionalmente, a nova estruturação da sociedade baseada nestas premissas tomou forma da objetivação das estruturas racionais e esta marca da modernidade permitiu que a razão invadisse todos os âmbitos da vida social. É no contexto desta modernidade que surgem as condições para que se desenvolvam as ciências e o discurso racional em geral como os conhecemos hoje. Quando um autor se utiliza deste tipo de discurso racional, portanto, ele está invocando uma série de pressupostos teóricos e comunicativos historicamente construídos e não por isso menos válidos: a existência de um sujeito, a possibilidade de validade de um ato de fala e seu reconhecimento, etc. (REPA in NOBRE, 2011, p. 296). Quando o próprio conteúdo da fala nega seus pressupostos, existe um vício no nível comunicativo ou pragmático. Luiz Sérgio Repa reconstrói de modo simples e muito fiel o argumento de Habermas. Um ato de fala possui dois elementos, um locucionário e um ilocucionário. O locucionário diz respeito ao próprio conteúdo da fala. O ilocucionário trata das pretensões de validade e condições pragmáticas em geral da comunicação, ou seja, do aspecto concreto e intersubjetivo, extrínseco à própria enunciação. A contradição performativa surge da incongruência entre os dois aspectos (REPA in NOBRE, 2011, p. 295). Não podemos colocar em palavras melhores que as do próprio professor:

Tomemos como exemplo o enunciado 'Não existe nenhuma verdade'. Se ele é empregado como conteúdo proposicional em um ato de fala realizado por alguém, portanto dotado de pretensões de validade, ocorre uma contradição entre a pretensão de validade de verdade e o conteúdo proposicional. Essa contradição se mostra quando se explicita a pretensão de validade: 'É verdade que não existe nenhuma verdade'. O elemento locucionário se choca, portanto, com o elemento ilocucionário. Mas os pressupostos pragmáticos não se 
referem somente à pretensão de validade. Como também a todas as condições em que ela pode ser erguida e cumprida. Tomemos o enunciado 'Eu não existo aqui e agora'. Em um ato de fala, esse enunciado implica uma contradição, pois precisa ser dito por alguém que existe no mundo aqui e agora. (REPA in NOBRE, 2011, p. 296).

Robert Vachon pode nos servir como um excelente exemplo do funcionamento da contradição performativa dentro de um estudo antropológico. Ainda, lançar um olhar sobre sua obra é interessante pois ele representa muito bem a forma pela qual funciona o pensamento antropológico mais recente. Utilizaremos por base seu texto L'Étude du Pluralisme Juridique. Neste, Vachon tem interesse primeiramente em mostrar como nosso pensamento acerca do Direito é carregado de pressuposições e prejuízos, as quais mesmo no estudo da antropologia jurídica constituem um obstáculo a uma verdadeira interlocução com outros povos e suas formas jurídicas. É parte muito relevante de seu pensamento afirmar que o Direito ${ }^{6}$ não se constitui exclusivamente de elementos racionais. Na verdade, o efetivamente essencial ao fenômeno jurídico é sua dimensão mítica, aquilo que no Direito mobiliza a experiência que determinado grupo tem do mundo. São aspectos afetivos e simbólicos que não funcionam sempre sob um regime de comensurabilidade. Ele trabalha então com esta distinção entre logos e myhtos (quiçá se poderia enxergar nesta distinção um eco do par apolíneo/dionisíaco).

Um exemplo muito claro de como Vachon opera com esta distinção no texto pode ser encontrada no momento em que se fala sobre o princípio de não contradição. Encontrando suas raízes no pensamento de Parmênides e sua formulação clássica na Metafísica aristotélica, o princípio de não contradição é uma regra fundante da lógica e da filosofia no ocidente. Afirma-se que algo não pode ser, sob o mesmo aspecto, duas coisas simultaneamente. Assim, percebe-se a perfeita identidade de algo a si mesmo. Através da aquisição desta herança cultural, isto se reflete na estruturação subjetivista de nosso Direito. Uma pessoa pode efetivamente ter uma posição jurídica já que é um indivíduo, distinto de todos os outros. Já entre os povos primitivos, a "individuação" ocorre pela percepção da participação de cada pessoa na ordem cósmica, pela medida em que cada um exprime a ordem cósmica do ser (os autóctones de Vachon são curiosamente um tanto quanto espinosistas). Assim, a experiência de identidade entre os seres que os indígenas experimentam não é da ordem do plenamente racionalizável, existe nela algo de incomensurável que é justamente o que a torna mítica. Nós podemos aprender algo desta experiência de deslocamento da subjetividade a partir do "diálogo dialogal”.

Não estamos neste momento nos preocupando muito com as distinções Direito/direito ou Direito/Juricidade. Sempre estamos nos referindo ao fenômeno jurídico mais amplo; quando não, o indicaremos. 
Contudo, qual o ponto de ser capaz de "aprender de dentro" o funcionamento da experiência de mundo indígena? Ora, isto é necessário para que a ciência, a disciplina, antropologia jurídica, possa melhor realizar sua tarefa. Pois bem. Contudo, qual o ponto em realizar este deslocamento, em nos fazer adquirir as estruturas do mythos, já que isto será mobilizado dentro do pensamento acadêmico, portanto, do pensamento do logos? Ora, certamente que as estruturas de um trabalho acadêmico, pautadas nos pressupostos enunciativos, não comportam a inserção efetiva da negação do princípio de não contradição. Pensemos como afirmou o professor Repa, que citamos mais acima: Vachon aceitaria por consequência de seu trabalho que as afirmações feitas no âmbito de seu estudo não tenham valor de verdade em sentido próprio? Que elas possam ser ou não ser verdadeiras? Certamente que não. O texto que estamos comentando é um trabalho acadêmico publicado numa revista especializada. Não se trata da linguagem do mythos, não está aqui este pensamento, mas sim o logos ocidental operando contra si mesmo, querendo eliminar os próprios pressupostos.

Vachon muito possivelmente não é o antropólogo mais renomado da atualidade, no entanto, seu trabalho nos revela uma forma de pensar muito característica da antropologia, especialmente daquela mais contemporânea. Bem como Bataille, que busca realizar a síntese da razão com seu oposto no estudo racional de objetos que de início a razão recusa superá-la em uma experiência erótica de dissolução do sujeito, Vachon tem a pretensão de por meio do recurso às formas de experiência de sociedades que não a nossa, ultrapassar não somente nossa compreensão eurocêntrica do Direito, mas sim algumas das próprias categorias discursivas que conformam nossa percepção do fenômeno jurídico. Por mais que sua crítica à ocidentalidade e à modernidade não tenha um escopo tão amplo quanto a de Bataille, incorre-se em contradição performativa inevitavelmente. A contradição performativa é a objeção de caráter genérico que Habermas opõe a toda forma de discurso filosófico que busca superar a modernidade, e portanto quer de algum modo livrar-se da razão. Portanto, em sua formulação mais própria, não se dirige à antropologia. Não obstante, parece perfeitamente razoável pensá-la deste modo quando a antropologia se revela com as mesmas pretensões que a filosofia pós-moderna. Até porque, vários dos autores incluídos nesta corrente dependem fortemente de considerações da antropologia, as quais são mobilizadas e implantadas em sua filosofia. O recurso constante à antropologia na obra de Bataille, por exemplo, diz muito sobre como existe entre ambas forte afinidade. Existe porém uma forma de se criticar a modernidade sem que se incorra em contradição performativa; um limite na tese que se encontra já a partir de sua própria formulação e o próprio Habermas reconhece. Apenas existe contradição performativa quando o ato de fala possui pretensão de validade de verdade. Ora, isto serve para os discursos científicos (a exemplo da antropologia), aqueles realizados na filosofia, os atos de fala "racionais" tout court. Contudo existem aqueles que não têm pretensão de validade, casos em que 
dizer "Não existe nenhuma verdade" ou "Eu não existo aqui e agora" é perfeitamente razoável. Trata-se da expressão literária.

O Iluminismo propõe como uma guia geral o abandono do mito e a adoção da razão como parâmetro único para guiar o homem em sua experiência do mundo (ADORNO; HORKHEIMER, 2006, p. 17). Isto parece muito razoável, e até então, alguns autores expressivos do Iluminismo tentarão por meio da razão fundamentar a existência de Deus, de normas morais ou jurídicas, etc. Existe certa radicalização dentro do próprio movimento quando se percebe que talvez tentar realizar este movimento seja apenas mistificação. Com Sade, este tipo de pensamento será elevado à potência máxima. Podemos seguir pelo caminho de Adorno e Horkheimer (2006, p. 80) e notar que o Iluminismo, em sua formulação mais própria, apoia-se necessariamente em um resquício de fé, de mito. A versão sádica (não sadeana, sádica) do Iluminismo leva a ideia de esclarecimento - a saída da menoridade, a capacidade de fazer uso do seu próprio entendimento sem auxílio de outrem - ao extremo no qual ela deve eliminar o mito que é parte constitutiva do Iluminismo tanto quanto o esclarecimento, mesmo que de modo indesejado. O catolicismo e o projeto utópico de civilização Iluminista são vistos apenas como mitos e assim condenados pela razão. Todo comportamento que é proscrito sob o fundamento de sua incivilidade, portanto, perde o fundamento de sua proibição e se torna moralmente indiferente. Praticar estes comportamentos bestiais é simplesmente proceder à catequese do maior de todos os pagãos, o homem civilizado (ADORNO; HORKHEIMER, 2006, p. 81). De qualquer modo, isto serve apenas para introduzir; quando trata-se de olhar para Bataille lendo Sade, devemos começar pela consideração de que Sade ao mesmo tempo realizou e criticou o sistema do Iluminismo em todas as suas consequências (BATAILLE, 2013b, p. 193). É justamente no âmbito desta ambivalência que se encontra seu mérito. Vimos como Vachon aponta algo neste sentido, mesmo que não desenvolva a afirmação em todas suas consequências. A razão e a ciência são os mitos da sociedade moderna, cumpre recusar tudo aquilo em que se tem fé cega, é necessário que a antropologia esclareça o esclarecimento (VACHON, 1990, p. 169). As semelhanças, se não param por aí, não vão muito além.

A razão, a princípio, recusa a experiência do extremo. O procedimento de Sade será obrigá-la a trabalhar com este extremo, inseri-lo violentamente nela. A afinidade entre racionalidade e interdito poderia parecer em um primeiro momento conflitar com o trabalho de Sade. Uma primeira instância disto se daria quando o autor em vários pontos de sua obra mostra seus personagens libertinos, que poderíamos dizer de certo modo serem parte do mundo heterogêneo da transgressão, utilizando-se de modos racionais do discurso filosófico e mesmo de aparatos técnicos para aumentar seu gozo. Não nos deixemos enganar por uma leitura superficial, os libertinos de Sade sentem um ódio fulminante pelo trabalho e pela produtividade. Em uma passagem interessante, Justine, 
após inocentemente tentar salvar um bebe da morte, é raptada por libertino cujo prazer é fazer engravidarem moças para após o parto matar seus filhos recém-nascidos. Para tornar viável a realização de suas lubricidades com a frequência necessária, ele criou uma máquina e todo um método, um verdadeiro procedimento terapêutico para aumentar a fertilidade de suas vítimas e garantir a fecundação com o mínimo de tentativas possíveis (SADE, 2013b, p. 229). Se seus métodos funcionassem de fato, seria ele um nome relevante na medicina contemporânea, mas sendo seus estudos apenas parte de uma obra de ficção libertina o que cabe ressaltar é como ele tomou os modos de funcionamento típicos da razão utilitarista e científica ao ponto de desenvolver um dispositivo técnico razoavelmente complexo cujo único fim era satisfazer sua luxúria infernal. Do trabalho realizado por ele, pode-se dizer que perdeu suas características intrínsecas de racionalidade, de âmbito da interdição, e passou a servir ao mundo da transgressão. Este seria, de acordo com a análise de Bataille, o procedimento sadeano de crítica da razão; fazer com que a razão passasse a operar em marcha a ré, contrariando seus próprios princípios. Deste modo a delimitação entre razão e desrazão, interdito e transgressão, fica prejudicada, já não podemos mais dizer que tipo de experiência se encaixa onde.

Inserido na obra "A Filosofia na Alcova" encontra-se um panfleto político chamado "Franceses, Mais um Esforço se Quereis ser Republicanos". Neste encontramse expostas de modo um tanto mais sistemático algumas ideias políticas do Marquês, inclusive referentes à natureza criminosa ou não do assassinato. Enquanto em um primeiro momento se nos afirma a falta de valor do homem perante a natureza, já que ele não custa a ela esforço algum ou ao menos nenhum esforço maior que o da geração de um animal comum, nesta passagem Sade ainda por cima nos lembra de como a natureza necessita da matéria que se encontra nos corpos para poder criar outros seres, de modo que a destruição é mais que sancionada, é necessária, é seu modus operandi. ${ }^{7}$ A violência, aqui pensada sob a forma do assassinato, é portanto mostrada como um bem que se faz à ordem natural das coisas (SADE, 2014, p. 161-162), fica comprovado que o crime não é imoral, nem ao menos amoral, irrelevante do ponto de vista da moralidade. Do ponto de vista de uma ética racional que busca seus fundamentos na natureza o crime é a ação moral por excelência, é um guia para a conduta humana. Estas são apenas algumas dentre tantas passagens que mostram a peculiar caracterização de Sade da natureza, um âmbito de violência desmesurada, destruição e gozo, no qual carrasco e vítima, tanto quanto homem e animal, são colocados como agrupamentos de matéria de igual valor, apenas aguardando o momento de seu retorno à natureza para serem reutilizados na produção de novos seres. Uma vez que a natureza ordena a imoralidade e o crime podemos ainda dizer

Ora, certamente que o leitor reteve em seu espírito a lembrança do argumento de Bataille que corre absolutamente no mesmo sentido deste. 
que nela o destrutivo tem mais valor que o construtivo, em suas leis o trabalho como o concebemos não tem lugar. Basta nos lembrarmos dos discursos libertinos de Coeur-deFer, que faz a apologia do onanismo e da sodomia remetendo-se ao desperdício de forças e materiais que a natureza corriqueiramente propala (SADE, 2012, p. 45). Podemos assim dizer que o heterogêneo está no mundo da transgressão, sendo caracterizado por ser o intocável, objeto de interditos e desejos simultaneamente, fora das leis, etc., enquanto que o homogêneo, aquele que trabalha, é da ordem do interdito. $\mathrm{O}$ que se percebe quando o autor faz com que a natureza passe para o lado do crime é a inversão do discurso Iluminista. $\mathrm{O}$ autor consegue fundamentar a sua moral da imoralidade do mesmo modo que os autores da época estavam tentando explicar sua moral racional. Neste panfleto, não só ele parte das premissas do Iluminismo, mas está se propondo a radicalizar e levar a cabo efetivamente a Revolução Francesa (ser republicano), sendo que ao fim acaba por subverter o que geralmente entendemos por elas.

Assim também se responde a uma segunda questão que o texto de Sade nos põe em relação à oposição entre racionalidade e transgressão. Esta se refere à própria forma narrativa escolhida pelo autor. Notamos mais acima como Sade faz um texto analítico, frio, em muitas passagens racional e argumentativo. Bataille define: é preciso "resignação para lê-lo" (BATAILLE, 2013b, p. 219). Poderia parecer uma incongruência falar de transgressão, narrar uma violência. Bataille mesmo considera a violência como um silêncio, algo que a linguagem teima em negar e excluir da existência por causa de sua própria incompatibilidade, sem sucesso (BATAILLE, 2013b, 215). Porém, ao pôr a brutalidade em palavras, Sade desvirtua a linguagem e a racionalidade assim como o excesso faz com o trabalho. Utilizando-se dos mecanismos lógicos que a frieza de sua narrativa lhe torna disponíveis, aumenta o gozo (BATAILLE, 2013b, 221), e consequentemente a violência, ao ponto de ser ela uma violência contra a própria razão. Como nota Pierre Klossowski, ao utilizar-se de categorias lógicas que constituem o próprio ato de escrever para justificar o ilógico, o ateísmo absoluto que leva à prostituição universal, Sade torna a razão contraditória, assim efetuando uma crítica a ela (KLOSSOWSKI, 1984, p. 17-18). Bataille reconhece isto como o inserir na consciência o seu oposto (BATAILLE, 2013b, p. 222). A racionalização da transgressão é o ponto chave de sua crítica à modernidade. Toda transgressão a princípio é irracional, ela toca aquilo que aterroriza, que está por debaixo das fundações do sujeito. Transgredir necessariamente causa no sujeito uma forte reação (BATAILLE, 1989, p. 142). Sade, ao obrigar seus libertinos a repetirem vezes sem fim as transgressões em todas suas variações possíveis, esfria seu potencial afetivo, desgasta os sentidos. Daí a necessidade de se recorrer a crueldades sempre mais intensas (BLANCHOT, 1963, p. 257-258). Esta é justamente a lógica interna de "Os 120 Dias de Sodoma". Sade deixou escrito o primeiro livro da obra, o resto apenas nos deixou o plano. Sabemos que as narrativas das quatro prostitutas, entremeadas pelas lubricidades 
dos quatro libertinos, que constituem o corpo da obra, aumentam de intensidade tanto dentro de cada livro quanto de um livro a outro. Assim, no primeiro livro, começamos com histórias de raptos de crianças, blasfêmias, desvirginamentos (SADE, 2006, p. 73), e terminamos com estupros e ameaças de assassinato (SADE, 2006, p. 289). No quarto livro, porém, o Marquês planejara relatar as mais excruciantes torturas, mutilações e execuções (SADE, 2006, p. 328), terminando com a descrição aflitiva de um método que chama de "inferno", a execução simultânea de várias moças mutiladas em uma orgia digna do nome que recebera (SADE, 2006, p. 353). Isto se explica quando consideramos que os libertinos, estando murados por vontade própria dentro de um castelo por quatro meses (SADE, 2006, p. 53), deixam de sentir atuar sobre si o interdito na medida em que a transgressão se torna cada vez mais reiterada. Por isto é necessário sistematizar o ato transgressor, para garantir que ele sempre atingirá algum limite ainda não explorado. Como logo acima dissemos, deste modo fica a própria consciência desvirtuada pelo regime de excesso ao qual é submetida. Com base nestas considerações respondem-se às incongruências que parecem surgir na obra de Sade quando fazemos uma primeira leitura. O uso da razão e da linguagem tanto pelo autor quanto pelos personagens não descaracteriza a extrema violência da obra, serve sim para desvalorizar uma razão que passa a ser obrigada a trabalhar em sentido oposto ao que normalmente lhe cabe. Respondidas estas objeções que se poderiam fazer a Sade, fica ainda mais clara a proximidade entre o autor e Bataille no que tange à noção de transgressão. Em ambos trata-se da aproximação com a natureza, mas entendida esta em um sentido próprio, como âmbito do dispêndio, da crueldade e da irracionalidade dentre outros adjetivos mais que a qualifiquem. E não se trata também de um mero retorno. Uma vez que se coloca a natureza sob o signo da proibição, toda tentativa de retorno a ela será sempre mediada pela recusa da cultura.

O Direito está inserido no âmbito dos interditos, mas ele não escapará deste movimento de subversão. Consideremos ainda "Os 120 Dias de Sodoma”. Os quatro libertinos isolam-se em um castelo para realizar suas orgias celeradas. Ora, lá as leis não poderão jamais atingi-los. Ainda assim, sem esta tensão, sem sentir pesar sobre si o jugo da proibição de seus atos, seu prazer jamais será completo. Por isto que eles percebem a necessidade de criar para si leis que os impeçam de praticar absolutamente tudo o que desejam em qualquer momento, mas garantam este desabrochar ritmado do mal. Assim, em muitas passagens os libertinos buscarão realizar algumas práticas que sua lei não permite naquele momento. Quando isto ocorre, eles são obrigados a recorrer a uma forma acessória de gozo, ${ }^{8}$ o que lhes dá um prazer enorme (SADE, 2006, p. 114), justamente

Quando dizemos isto estamos pensando nas reiteradas passagens em que eles sentem ganas de desvirginar seus escravos sexuais, mas, proibidos, devem satisfazer-se com outras formas de relação que lhes garantem muito prazer. 
por fazer sentir a proibição na iminência de ser transgredida. Ainda, a relação que eles estabelecem entre punição e prazer é algo a ser considerado. Quando um de seus sujeitos (poderia Sade ter escolhido uma designação melhor para aqueles que são as vítimas dos quatro celerados? lembre-se o leitor sobre como estamos tratando aqui de questões da filosofia da modernidade, que constitui-se basicamente sobre a categoria do sujeito) fere alguma lei de seu ordenamento interno, ele são punidos em uma espécie de sessão pública misturada com orgia, obviamente, na qual a finalidade é, muito mais que corrigir os desvios e garantir o bom andamento dos planos dos libertinos celerados, dar-lhes prazer pela tortura infligida ${ }^{9}$ (SADE, 2006, p. 70). É comum nas cenas sádicas a associação da punição das personagens com o prazer lúbrico de seus carrascos. Esta lógica é reiterada em Justine, na qual ainda salta aos olhos o fato de que Justine é punida não por seus crimes, mas sim quando realiza boas ações, como, por exemplo, seu maior período de cativeiro, em uma abadia, que tem ocasião quando ela deseja visitar uma estátua santa (SADE, 2012, p. 125-126). Faz algum sentido quando pensamos na moral natural de Sade, que prescreve como correto justamente a má conduta, a destruição (SADE, 2014, p. 161).

Uma coisa interessante a se considerar é que se o Direito é do âmbito dos interditos fica excluída de partida a possibilidade de um Direito natural (SADE, 2014, p. 162). Pelo contrário, se desejamos pautar-nos pela razão natural, devemos abandonar todo projeto de estabelecer um Direito no sentido forte. Na natureza vigora uma anarquia primordial, alguma espécie de vertigem dionisíaca (claro que Sade nunca usou esses termos, mas ajudam a entender o que se passa). Aqui, não cabe falar nas distinções entre sujeito e objeto nem entre sujeitos. Por isto que o libertino também sente prazer sendo vítima da libertinagem, não apenas supliciando. Roland pede em uma cena para que Justine se use de um de seus aparatos técnicos feito especialmente para matar as vítimas sufocadas para que ele possa saber como elas se sentem. Ele acredita (e na verdade estava certo) que elas tinham um enorme prazer enquanto morriam. Justine foi a escolhida para operar a máquina pois Roland sabia que Justine interromperia a operação antes de sua morte, apenas com tempo suficiente para que ele sentisse a lubricidade de ser vítima (SADE, 2013, p. 705). Mas isto ilustra bem como as posições são intercambiáveis quando se está na lógica do prazer; este circula entre vítimas e carrascos igualmente. Tal consideração é muito relevante quando temos em mente que a partir do Código Napoleônico, o principal legado jurídico decorrente da Revolução Francesa, portanto da modernidade, a categoria central

9 Note-se que Sade não chegou a propriamente inserir as cenas de punição, já que elas seriam impróprias na primeira parte do livro onde se narram apenas as paixões mais fracas dos libertinos e as outras seções apenas ficaram esboçadas de modo muito incipiente. Existem algumas passagens no quarto livro que podem se referir às punições, mas não sabemos bem. 
do estudo do Direito é a de sujeito de direitos. Sem entrar em detalhes técnicos acerca desta noção, podemos dizer que de qualquer modo trata-se da constituição da subjetividade, ou seja, do isolamento do indivíduo em uma estrutura reflexiva autorreferencial, no âmbito da atividade jurídica. Ora, quando passamos a considerar a crítica à modernidade sadeana, é a perspectiva do sujeito que fica prejudicada. Este na atividade erótica se dissolve, bem como Deus ao se consubstanciar pode ser três e um simultaneamente (SADE, 2001, p. 254). O ponto central talvez seja este, de que quando se está envolvido neste tipo de atividade, as categorias da razão não operam mais perfeitamente, os sujeitos realizam um retorno à natureza mediado pelas interdições que se opuseram à própria natureza e lhe dão a sensação da transgressão. E ainda mais, deve-se reconhecer que sobre toda atividade racional se lança a maldição de sua origem, que é esta própria natureza violenta, o oposto da razão que nunca realmente se exclui, mas se pressupõe. Como pensar um Direito que é não pautado na experiência da subjetividade, e portanto não adianta tentarmos mudar o foco para uma intersubjetividade ou transubjetividade ou coisa que o valha, mas sim em uma experiência de não subjetividade, de dissolução dos sujeitos entre si e com seu entorno objetificado? A antropologia talvez dê a resposta. Pelo menos parece que é isto que Bataille pensa, especialmente a respeito da antropologia do dom, as sociedades do potlacht. Sade não tem uma resposta positiva à questão, buscá-la exige um trabalho à parte. Certamente, ele aponta para a existência de uma juricidade imoral ou até mesmo uma completa anarquia que se resolve na lei do mais forte. De qualquer modo, mais importante que marcarmos a posição do autor a este respeito, o que queríamos era deixar claro, e deixamos, como Sade oferece um paradigma de radicalidade absoluta na crítica ao Direito a partir de sua reflexão sobre a vivência histórico-moral do ocidente que não se enreda na contradição performativa.

O que se quer dizer é não só que a literatura oferece um paradigma crítica mais consistente do ponto de vista de seus pressupostos enunciativos que o da antropologia. Quando consideramos que a contradição performativa diz respeito muito fortemente à análise que Habermas faz da modernidade, percebemos que o verdadeiro problema é que a antropologia não consegue de modo algum ir longe o suficiente em seu descentramento. Para tanto, ela precisaria ser capaz de se desvencilhar das próprias categorias de pensamento que lhe dão seu embasamento teórico. Justamente este o ponto, para ser capaz de efetivamente se por para além da ocidentalidade moderna que pretende criticar, a antropologia precisaria renunciar a suas pretensões de teoria. Não que a literatura se encontre de fora por completo da experiência da modernidade e do ocidente. Contudo, a obra de Sade nos revela desta modernidade e desta ocidentalidade seu outro, o que restou excluído pelos rumos da história e da cultura. O que realmente importa nesta obra é que ela não está atrelada a alguns dos fundamentos mais íntimos do pensamento moderno. Se ela busca revelar o que ficou excluído, ela o faz por meio de uma forma de escrita 
que também restou à margem do processo modernizador: a linguagem da violência e da vítima. Sade foi, por excelência, a vítima da Revolução Francesa, a vítima dos primeiros passos da modernidade; no resto não contabilizado do processo modernizador estão Sade e seu pensamento. Vachon, enquanto um representante do pensamento antropológico mais recente, quer nos trazer à consciência formas de experiência que foram renunciadas pela história do pensamento no ocidente. Contudo, seu discurso é a forma do discurso ocidental, sua linguagem é a linguagem do aufklärer. O que queremos mostrar, e acreditamos em certa medida tê-lo feito, não é a inutilidade ou um vício insuperável no projeto crítico da antropologia; mas sim como ele, em seus limites, pode apontar para a literatura (especialmente formas marginalizadas de literatura, como a erótica) e a arte como um todo como sendo uma alternativa ainda mais radical para se criticar a modernidade.

São Paulo, julho de 2016.

Referências

ADORNO, Theodor W.; HORKHEIMER, Max. Dialética do esclarecimento: fragmentos filosóficos. Rio de Janeiro: Jorge Zahar, 2006.

BATAILLE, Georges. A parte maldita. Precedida de "A noção de dispêndio". São Paulo: Autêntica, $2013 a$.

BATAILLE, Georges. La Structure psychologique du fascisme. Hermès, La Revue, Paris, n. 5-6, p. 137-160, 1989.

BATAILLE, Georges. O erotismo. São Paulo: Autêntica, 2013b.

BLANCHOT, Maurice. Lautréamont et Sade. Paris: Éditions de Minuit, 1963.

HABERMAS, Jürgen. Arquitetura moderna e pós-moderna. Tradução: Carlos Eduardo Jordão Machado. Novos Estudos CEBRAP, São Paulo, v. 2, n. 18, p. 115-124, set. 1987.

HABERMAS, Jürgen. Teoria do agir comunicativo. São Paulo: WMF Martins Fontes, 2012.

HABERMAS, Jürgen. The philosophical discourse of modernity. Cambridge: Polity Press, 2007.

KLOSSOWSKI, Pierre. Sade, meu próximo. São Paulo: Brasiliense, 1984.

MACHADO, Roberto. Zaratustra, tragédia nietzschiana. Rio de Janeiro: Jorge Zahar Editor, 1997.

MARTON, Scarlett (Org.) Nietzsche, um “francês” entre franceses. São Paulo: Discurso Editorial: Barcarolla, 2009.

MELTZER, Françoise. Sobre a questão da Aufhebung: Baudelaire, Bataille e Sartre. Revista Crítica de Ciências Sociais, Coimbra, v. 75, p. 3-19, 2006. 
MORAES, Eliane Robert. Lições de Sade. Ensaios sobre a imaginação libertina. São Paulo: Iluminuras, 2006.

MORAES, Eliane Robert. Marquês de Sade: um libertino no salão dos filósofos. São Paulo: EDUC, 1992.

MORAES, Eliane Robert. Sade: a felicidade libertina. Rio de Janeiro: Imago, 1994.

NIETZSCHE, Friedrich. Ecce homo. Tradução: Paulo César de Souza. São Paulo: Companhia das Letras, 2008.

NIETZSCHE, Friedrich. O nascimento da tragédia. São Paulo: Companhia das Letras, 2012.

NOBRE, Marcos (Org.). Curso livre de teoria crítica. 3. ed. Campinas: Papirus, 2011.

ROULAND, Norbert. Nos confins do direito: antropologia jurídica da modernidade. 2. ed. São Paulo: WMF Matins Fontes, 2008.

SABOT, Philippe. Bataille, entre Kojève et Queneau: le dèsir et l'histoire. Le Portique: Revue de Philosophie et de sciences Humaines, Strasbourg, v. 29, p. 19-35, 2012.

SADE, Marquês de. [Donatien Alphonse François de Sade]. A Filosofia na alcova. Tradução, posfácio e notas Contador Borges. São Paulo: Iluminuras, 2014.

SADE, Marquês de. [Donatien Alphonse François de Sade]. Justine. Milão: Mondadori, 2012.

SADE, Marquês de. [Donatien Alphonse François de Sade]. La nuova justine. Parma: Ugo Guanda, 2013.

SADE, Marquês de. [Donatien Alphonse François de Sade]. O Corno de si próprio e outros contos. Organização e tradução de Plínio Augusto Coêlho. São Paulo: Hedra, 2009.

SADE, Marquês de. [Donatien Alphonse François de Sade]. Opere. Milão: Mondadori, 2001.

SADE, Marquês de. [Donatien Alphonse François de Sade]. Os 120 dias de sodoma. Tradução: Alain François. São Paulo: Iluminuras, 2006.

VACHON, Robert. L'etude du pluralisme juridique: une approche diatopique et dialogale. The Journal of Legal Pluralism and Unofficial Law, [S. 1.], v. 22, n. 29. p. 163-173, 1990.

VENTURI, Robert; BROWN, Denise Scott; Izenour, Steven. Learning from Las Vegas. Cambridge: MIT Press, 2001. 
